\section{Good Eggs and Old Age}

THE man or woman who lives to be eighty years old started as an "extraordinarily good egg" is a conclusion stated by Dr. George L. Streeter, director of the Department of Embryology of the Carnegie Institution of Washington, according to Science Service, Washington. Human eggs, like hen's eggs, vary greatly in nature and quality. It is estimated that one fourth of the fertilised human ova are not good enough eggs to be born as living individuals. Whether the infant survives its first year-and, in fact, a large number of them fail to do thisdepends in considerable part on the original quality of the egg. The individual who withstands the usual experiences of life until between fifty and sixty years old and then succumbs to its aggregate wear and tear, conforms to the actuary's 'expectation of life at birth' and to the embryologist's expectation of the performance of an egg of average quality. It is only the extraordinarily good egg that is still going strong at eighty years, and we see him or her doing this in the absence of any exquisite hygienic regime or environmental favour.

\section{Plant Collecting in Persia}

'THe Gardeners' Chronicle is always to the fore in publishing reports of expeditions organised for the collection of new plants. In the issue of January 6 appeared the first of a new series of articles on "Plant Collecting in Persia" by Mr. E. K. Balls. The account gives full descriptions of the habitats of a wide variety of plants, particularly irises, campanulas, gentians and Dionysia. More intimate details of the trip are also included. The second article appeared in the issue of January 20, and articles are promised for some time ahead. If the plants collected prove amenable to cultivation in Great Britain, many beautiful species will be placed at the disposal of gardeners.

\section{International Union for Chemistry}

Tнш eleventh conference of the International Union for Chemistry will be held at Madrid at the same time as the ninth International Congress of Pure and Applied Chemistry. Among the matters to be considered by the various commissions of the Union are the reforms of inorganic, organic and biochemical nomenclature; physico-chemical standards ; co-ordination of scientific terminology ; international tables of constants; and finance. The election of president and vice-presidents, and the nomination of members of commissions, will take place on April 11.

\section{International Congress of Actuaries}

THE Tenth International Congress of Actuaries will be held at Rome on May 4-10. The subjects for discussion will cover a large field and particular attention is being given to different aspects of social insurance, including unemployment insurance. Various social functions and excursions have been arranged and the Congress promises to be one of the most interesting of recent years. The British Government has appointed as its representative the Deputy Government Actuary, Mr. G. S. W. Epps. It is hoped that those Cabinet Ministers whose Departments are specially concerned with actuarial questions will be associated in an honorary capacity with this as with past congresses. Membership of the Congress is open to members of the Permanent Committee of International Congresses of Actuaries and, subject to approval by the Managing Committee, to others or institutions professionally associated with actuarial work. Further information can be obtained from Mr. Geoffrey Marks, C.B.E., 39, King Street, E.C.2, or Mr. Stuart Cumming, 19, St. Andrew Square, Edinburgh.

\section{International Agricultural Congress}

THE third Technical and Chemical International Congress of Agricultural Industries will be held in Paris on March 26-31. The Congress will be followed by a tour of the French wine-growing districts, arranged so that those delegates who wish can continue to Madrid in time for the opening of the ninth International Congress of Pure and Applied Chemistry on April 5. The work of the Congress is divided into five main sections : scientific and economic studies; sugar manufacture; fermentation industries; food industries; and allied industries. The subjects selected for discussion cover a wide range, but will be chiefly of interest to technologists in the sugar and fermentation industries. Other questions to be discussed include water pollution, and new uses for surplus agricultural produce, in Section 1; the properties of wheat and flour in relation to bread quality, and the treatment of milk from the farm to the consumer, in Section 4 ; the use of alcohol fuels and of vegetable oils in motors, in Section 5. These ensure that the Congress will appeal to a wide circle of agricultural and other technologists. Adequate arrangements have been made for relaxation from the more serious work of the Congress. The sub. scription for individual delegates is 100 francs, payable to the Treasurer, M. Combrun, 156 Boulevard de Magenta, Paris, from whom application forms and other details may be obtained.

\section{The Seventh Achema}

WE have received an illustrated leaflet which contains the preliminary announcement of the seventh 'Achema' or Exhibition of Chemical Plant and Apparatus, organised by the 'Dechema' (Deutsche Gesellschaft für chemische Apparatewesen), which will be held at Cologne during Whitsuntide (May 18-27). The event has been timed to coincide with the annual meetings in the same city of several of the leading German allied societies, and the exhibition will be held in three large buildings on the banks of the Rhine and within easy walking distance from the centre of the city. Four years will have elapsed since the sixth 'Achema' was held at Frankfort and the promoters confidently claim that this will be the greatest exhibition of its kind that has yet been held anywhere in the world. Most of the leading German firms who supply chemical plant and apparatus have already booked stands and a big 